\title{
ArcheoSciences
}

Revue d'archéométrie

33 (suppl.) | 2009

Mémoire du sol, espace des hommes

\section{Revealing the ancient city of Sikyon through the application of integrated geophysical approaches and 3D modelling}

Apostolos Sarris, Nikos G. Papadopoulos, Spilios Theodoropoulos, Ben Gourley, Guangrong Shen, Yannis Lolos et Thanasis Kalpaxis

\section{OpenEdition}

1 Journals

Édition électronique

URL : https://journals.openedition.org/archeosciences/1468

DOI : 10.4000/archeosciences. 1468

ISBN : 978-2-7535-1599-4

ISSN : 2104-3728

Éditeur

Presses universitaires de Rennes

\section{Édition imprimée}

Date de publication : 30 octobre 2009

Pagination : $143-146$

ISBN : 978-2-7535-0943-6

ISSN : $1960-1360$

Référence électronique

Apostolos Sarris, Nikos G. Papadopoulos, Spilios Theodoropoulos, Ben Gourley, Guangrong Shen, Yannis Lolos et Thanasis Kalpaxis, "Revealing the ancient city of Sikyon through the application of integrated geophysical approaches and 3D modelling », ArcheoSciences [En ligne], 33 (suppl.) | 2009, mis en ligne le 30 octobre 2011, consulté le 01 février 2022. URL : http://journals.openedition.org/ archeosciences/1468; DOI : https://doi.org/10.4000/archeosciences.1468 


\title{
Revealing the ancient city of Sikyon through the application of integrated geophysical approaches and 3D modelling
}

\author{
Apostolos Sarris*, Nikos Papadopoulos *,**, Spilios Theodoropoulos*, \\ Ben Gourley ***, Guangrong Shen ****, \\ Yannis Lolos ${ }^{* * * * *}$ and Thanasis KalpaXIs*
}

Key words: Sikyon, Geophysical prospection, 3D modelling, Wavelets, GIS.

The ancient city of Sikyon is located in the northern Peloponnese covering an area of 250 ha on a plateau that rises about $4 \mathrm{~km}$ southwest of the Corinthian gulf. Previous archaeological excavations revealed a limited number of monuments within the surroundings of the ancient agora. Since 2004, a consortium led by the University of Thessaly, the Institute for Mediterranean Studies/FORTH, the University of York and the 37th Ephorate of Prehistoric and Classical Antiquities initiated the Sikyon Survey Project with the aim of a detailed exploration of the cultural and environmental settings of the Hellenistic/Roman city of Sikyon through a combination of surface surveying and geo-informatics (Lolos et al., 2007). Emphasis was placed on groundbased geophysical prospection of the site which consisted of two main modules. The first module was concentrated on the city centre and explored the agora and its surroundings through a combination of various high resolution prospection techniques (magnetics, soil resistance, ERT, GPR). The other module focused on a wide coverage of the rest of the settlement through magnetic techniques complemented by intensive fieldwalking activities that aimed at covering most of the urban area.

The intensive exploration of the agora and its neighbouring areas was decisive for the investigation of the extent and cultural context of the feature, providing an insight into the relationship between the civic centre and the broader urban context. Magnetic methods employed two fluxgate gradiometers, FM256 by Geoscan Research and GRAD

\footnotetext{
* Laboratory of Geophysical - Satellite Remote Sensing \& Archaeo-environment, Foundation for Research \& Technology, Hellas (FORTH), Institute for Mediterranean Studies (IMS), Melissinou \& Nik. Foka 130, PO. Box 119, Rethymnon 74100, Crete, Greece. (asaris@ret.forthnet.gr)

** Korea Institute of Geoscience and Mineral Resources (KIGAM), Mineral Resources Research Division, Laboratory of Resource Exploration Development, 92 Gwahang-no, Tuseong-gu, Daejeon, 305-350, S. Korea.(nikos@ims.forth.gr.)

*** Department of Archaeology, University of York, Kings Manor, York, YO17EP, United Kingdom. (rbg4@york.ac.uk)

**** Laboratory of Digital Agriculture, School of Agriculture \& Biology, Shanghai Jiaotong University, No.800, Dongchuan Road,0086 200240,Shanghai, P. R. CHINA. (shengr6288@hotmail.com)

***** Department of History, Archaeology and Social Anthropology, University of Thessaly, Argonafton and Filellinon, Volos, Greece 38221. (lolos@ hol.gr)
} 
601 by Bardington Instruments, employed in a high resolution (0.5 m sampling) mode. A Geoscan Research resistivity meter RM15 with a multiplexer MPX15 and a twin probe electrode configuration with 0.5 and $1 \mathrm{~m}$ electrode separation covered large sections of the region and provided additional confirmation of the magnetic targets. Electrical resistivity tomography (ERT) and ground penetrating radar (GPR) techniques obtained information about the vertical extent and depositional history of selected features. A Sensors \& Software EKKO 1000 unit and a Noggin Plus Smart cart with 225 and $450 \mathrm{MHz}$ antennas generated detailed stratigraphic images of specific architectural monuments and scanned areas where surveying conditions were problematic (e.g. asphalt roads, concrete parking lots, etc.) (Sarris et al., 2008).

Both magnetic and soil resistance measurements in the agora provided a detailed plan of the subsurface architectural features, which together with the preserved surface monuments enabled us to reconstruct the urban centre of Sikyon. The council-chamber (bouleuterion) and the long stoa, both of which were partly excavated in the past, were mapped in detail. The east limits of the agora were defined by the palaestra and a large peristyle building to the north of the excavated palaestra complex, containing a small tripartite building $(10 \times 6 \mathrm{~m})$ similar to a temple with pronaos and opisthodomos. The historical evolution of the site was suggested by the discovery of a Byzantine basilica $(30 \times 18 \mathrm{~m})$ at the centre of the agora, consisting of an inner and outer narthex. The rest of the geophysical anomalies within the context of the agora did not demonstrate regularity in their provision. Other large structures were also identified to the north of the stadium and to the north of the theatre, as well as in the surroundings of the Roman baths that are currently used as a site museum.

Controlled experiments using two separate ERT approaches were run in two different parts of the agora. The region above the basilica at the centre of the agora was scanned with a conventional ERT approach employing a Syscal Pro
ERT unit with a 10-channel multiplexer module (Switch Pro) and a Dipole-Dipole electrode configuration. A second region. covered by a $15 \times 10 \mathrm{~m}$ rectangular grid, located north of the palaestra above the small tripartite building/ temple, was scanned using the RM15/MPX15/PA5 system of Geoscan Research with a pole-pole electrode configuration with inter-electrode and inter-line spacing of $0.5 \mathrm{~m}$ and maximum electrode separation equal to $\mathrm{N}_{\max }=4 \mathrm{a}(\mathrm{a}=0.5$ $\mathrm{m})$. In both cases, data were collected along a network of parallel, single direction transects, and were processed using a 3D Finite Element Method (FEM) resistivity inversion algorithm (Papadopoulos et al, 2007; Tsourlos \& Ogilvy, 1999). The reconstructed resistivity models $(\% \mathrm{RMS}<5)$, in the form of horizontal slices of increasing depth, indicated the outline, inner divisions and different construction phases of the structures apparently extending down to $1.75-1.00 \mathrm{~m}$ respectively below the current surface (Fig. 1) (Sarris et al, 2008).

GPR measurements along the asphalt road that leads to Vasiliko village and the parking lot located to the south of the Roman baths revealed a number of features marking the north limits of the agora at a distance of about $120 \mathrm{~m}$ from the south stoa. GPR data also indicated a number of details and construction phases of the Byzantine basilica and the large peristyle structure (north of the palaestra), the north portico of which has a back wall with a series of semi-circular and rectangular niches. The ancient theatre was also scanned by a network of 19 GPR transects of variable length, the results suggesting a number of reflectors most probably related to the seats of the theatre (Fig. 2). Structural details of a number of subsurface complexes were clearly shown by the GPR slices (Fig. 2) in contrast to the ones shown by other, conventional methods.

Wavelet transform and unsupervised (ISODATA) classification techniques were used for the decomposition of the original geophysical datasets to eliminate the noise and achieve a fusion of data provided by the various prospection techniques. The accuracy assessment of the classified
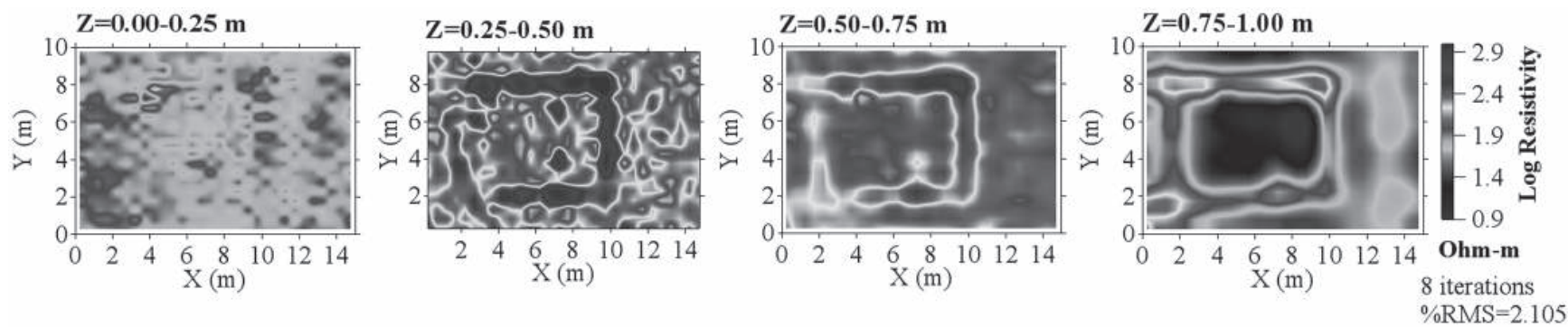

Figure 1: 3D inversion model from the area of the small building (temple) to the north of the Palaestra in the form of horizontal slices of increasing depth. The logarithm of the resistivity has been plotted. 

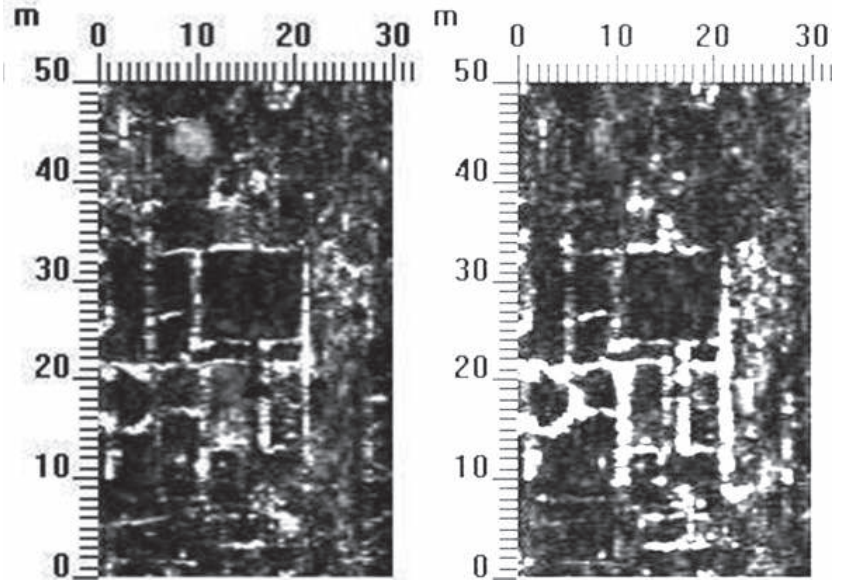

Figure 2: Left: Results from the GPR survey at the ancient theatre of Sikyon. The intense reflectors (white) indicated the location of the seats of the theatre. Right: Horizontal slices of the GPR survey above a residential quarter to the east of the agora for depths of $80-90 \mathrm{~cm}$ and $110-120 \mathrm{~cm}$ (from left to right).

image (overall classification accuracy $89 \%$ and overall Kappa statistics 0.789 ) was performed by selecting and comparing the consistency of a set of 200 random points in the classified image and the original images. The subsequent wavelet decomposition (using the sym 4 wavelet basis) and reconstruction through various fusion techniques (using mainly the detailed-high frequency image) proved satisfactory for the elimination of original data noise (Fig. 3). The quality of the denoised images was evaluated through computation of a normalized mean squared error (Shen et al., 2007).

At the periphery of the city, a more extensive magnetic survey with a sampling of $0.5 \times 1 \mathrm{~m}$ was tuned to the general strategy of the fieldwalking survey through the scanning of corresponding surface survey tracks, thus providing sufficient information about the correspondence between the surface distribution of sherds and subsurface manmade features across most of the region (Gourley et al., 2008). The particular module of research indicated a number of architectural relics and provided us with enough data to reconstruct the ancient city-grid. More specifically, it was shown
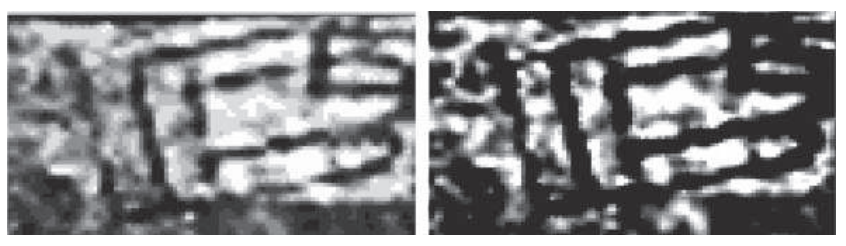

Figure 3: Classified magnetic data (left) and result of the fusion between the classified magnetic image with the denoised resistivity image (right). that most of the habitation quarters of the city extend to the north, east and south of the agora, whereas the upper plateau (to the southwest of the agora and the theatre) was set aside for agricultural and pastoral activities. Furthermore, the combined geophysical approaches suggested a system of land division and a formalized town planning consisting of an orthogonal grid of streets (N-S and E-W orientation) extended over the entire lower plateau.

The simplified geophysical interpretation was used as the basic ground plan in $3 \mathrm{D}$ software providing the exact position and dimensions of the main buildings of the agora. The descriptions offered by the 2 nd century AD traveller Pausanias and plans from the old excavations in the agora were employed to create $2 \mathrm{D}$ models of several buildings. These are the data we imported to create a low polygon model of the Bouleuterion and the Stoa overlaid on the high resolution satellite imagery of the site obtained by Quickbird images. Using different techniques and tools of spline modification such as Hyper Nurbs, Extrude Nurbs and others, the wireframe was created giving rise to a complete high-polygon model. The refinement of the model was achieved using different materials constructed through a combination of relief, diffusion and alpha channel adjustments. Global illumination techniques were ultimately used for the final rendering of the models with realistic textures. In this way, the 3D models of the main buildings of Sikyon were constructed giving rise to a virtual reconstruction of the landscape of the ancient city (Fig. 4).

All geophysical data were rectified and imported in a GIS system used for synthesis between the survey results and the interpretation of geophysical anomalies. A Quickbird image was used as the background layer and the diagrammatic interpretation from each method was implemented in the system in vector format. In this way it was possible to relate the surface monuments with the raster surfaces of the concentration of sherds and the subsurface features sugges-

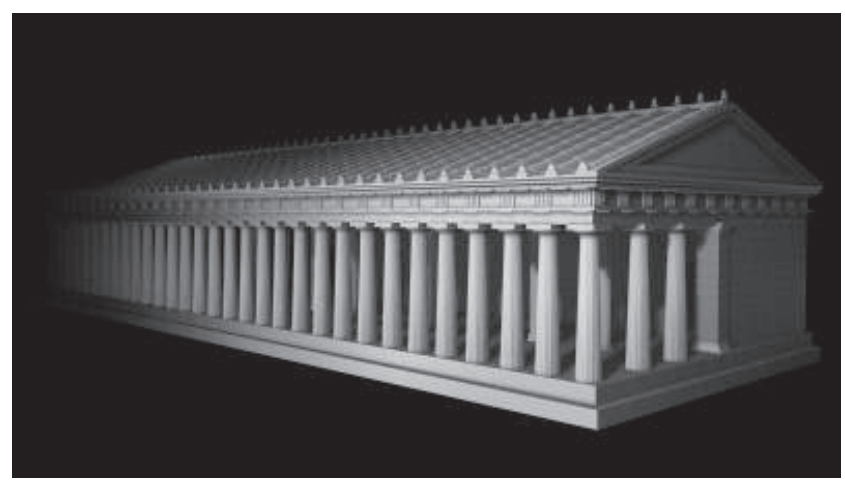

Figure 4: Low rendering 3D models of the south stoa. 
ted by the geophysical techniques. The geophysical survey provided significant information regarding the type and preservation of the subsurface architectural relics of the site, refining the interpretation of its historical evolution. Having established the limits of the agora and having mapped a number of structural remains inside and outside the agora including temples, porticoes, streets and residential quarters, it is possible to proceed towards a massive reconstruction of the ancient city and its later phases.

\section{References}

Gourley, B., Lolos, Y. and SARris, A., 2008. Application of Integrated Geophysical Prospection Techniques for Mapping Ancient Sikyon, Greece. In R. Lasaponara, N. Masini (dir.). Proceedings of the $1^{\text {st }}$ International EARSeL Workshop on Advances on Remote Sensing for Archaeology and Cultural Heritage Management, CNR, 1st edition, Rome, 169-173.

Lolos, Y., Gourley, B. and Stewart, D., 2007. The Sikyon Survey Project: A Blueprint for Urban Survey? Journal of Mediterranean Archaeology, 20, 267-296.

Papadopoulos, N. G., Tsourlos, P., Tsokas, G. N. and Sarris, A., 2007. Efficient ERT Measuring and Inversion Strategies for 3D Imaging of Buried Antiquities. Near Surface Geophysics, 5, 6, 349-362.

Sarris, A., Papadopoulos, N., Trigkas, V., Kokkinou, E., Alexakis, D., Kakoulaki, G., De Marco, E., Seferou, E., Shen, G., Karaoulis, M., Simirdanis, K., Kondili, F., Katifori, M., Dogan, M., Lolos, Y. and KalpaXis, Th., 2008. Recovering the Urban Network of Ancient Sikyon Through Multi-component Geophysical Approaches. In A. Posluschn, K. Lambers, I. Herzog (dir.). Layers of Perception. Proceedings of the 35th International Conference on Computer Applications and Quantitative Methods in Archaeology. (CAA), Berlin. Kolloquien zur Vor und Frühgeschichte v. 10, Bonn, 11-16.

Shen, G., Sarris, A. and Papadopoulos, N., 2008. Enhancing Geophysical Signals from Archaeological Sites Trough the Use of Wavelet Transforms. WSEAS Transactions on Systems, 7 (3): 140-147.

Tsourlos, P. and Ogilvy, R., 1999. An algorithm for the 3-D Inversion of Tomographic Resistivity and Induced Polarization data: Preliminary Results. Journal of the Balkan Geophysical Society, 2, 2, 30-45. 